\title{
Emodin inhibits the differentiation and maturation of dendritic cells and increases the production of regulatory $T$ cells
}

\author{
WEI ZHANG ${ }^{1 *}$, HONG LI $^{2 *}$, HEQI BU ${ }^{1 *}$, HUI CHEN ${ }^{1}$, HONGFEI TONG ${ }^{1}$, \\ DIANLEI LIU ${ }^{1}$, HONGCHUN GUO ${ }^{1}$ and SHENGZHANG LIN ${ }^{1}$ \\ ${ }^{1}$ Department of Surgery, The Second Affiliated Hospital of Wenzhou Medical College, Wenzhou 325027; \\ ${ }^{2}$ Wenzhou Vocational College of Science and Technology, Wenzhou 325000, P.R. China
}

Received August 11, 2011; Accepted September 26, 2011

DOI: $10.3892 /$ ijmm.2011.820

\begin{abstract}
The aim of this study was to characterize the effects of emodin on dendritic cells (DCs) and $\mathrm{CD} 4{ }^{+} \mathrm{CD} 25^{+}$regulatory T cells (Tregs). Myeloid DCs were prepared from peripheral blood mononuclear cells of healthy human donors and treated with emodin at different concentrations. The phenotype and T cell stimulatory capacity of these DCs were analyzed. The expression ratios of CD80 and CD83 in DCs in the presence of emodin $(100 \mu \mathrm{g} / \mathrm{ml})$ were significantly decreased compared with that in DCs without emodin treatment $(\mathrm{P}<0.05)$. IL-12p70 production of DCs decreased significantly with emodin treatment $(\mathrm{P}<0.05)$. Furthermore, an approximately 2 -fold decrease was observed in the ability of DCs pre-treated with emodin to induce T-lymphocyte proliferation. In addition, we found that emodin treatment increased the number of Tregs, which expressed lower levels of human leukocyte antigen (HLA-DR), glucocorticoid-induced tumor necrosis factor receptor (GITR), and cytotoxic T-lymphocyte associated antigen-4 (CTLA-4) as compared to cells without emodin treatment. Our results suggest that emodin inhibits the differentiation and maturation of DCs and induces Tregs, which may be helpful for the modulation of the immune rejection after liver transplantation.
\end{abstract}

\section{Introduction}

Emodin (1,3,8-trihydroxy-6-methylanthraquinone) is an active anthraquinone constituent of rhubarb extracts. It functions through its anti-atherosclerosis, anti-bacterial, anti-cancer, and vasorelaxant properties (1-6). The effects of emodin in protecting patients from both cerebral ischemia injury and myocardial ischemia/reperfusion injury have been associated with its role in inhibiting inflammation $(7,8)$. Further study revealed that emodin may be involved in the modulation of rejection of liver transplantation $(9,10)$.

Correspondence to: Dr Sheng-zhang Lin, Department of Surgery, The Second Affiliated Hospital of Wenzhou Medical College, No. 109 West Xue-yuan Road, Wenzhou 325027, P.R. China

E-mail: wzf21sz@163.com

*Contributed equally

Key words: emodin, regulatory T cells, dendritic cell
It is well known that dendritic cells (DCs) and regulatory $\mathrm{T}$ cells (Tregs) play a pivotal role in inhibiting the rejection of transplantation (11-15). DCs are professional antigen-presenting cells (APCs) that are specialized for the initiation and regulation of $\mathrm{T}$ cell immunity. The efficacy of DCs in activating $\mathrm{T}$ cells appears to correlate with quantitative aspects. For example, expression of MHC-peptide complexes is 10- to 100-fold higher in DCs than in other APCs, such as $B$ cells and macrophages. The function of DCs in organ transplantation has been defined, they can capture allogenic antigen and present it to specific $T$ cells to induce an immune response against donors $(11,12)$. Decreasing the antigen-presenting function of DCs is able to inhibit the rejection of transplantation by DC-induced tolerance (13).

$\mathrm{CD} 4^{+} \mathrm{CD} 25^{+}$Tregs play a vital role in the maintenance of self-tolerance (14-16). These $\mathrm{T}$ cells represent $5-10 \%$ of the human $\mathrm{CD}^{+} \mathrm{T}$ cell population. They are anergic, and thus do not proliferate in response to $\mathrm{T}$ cell receptor stimulation in vitro (17). Tregs express CD4CD25 (the interleukin 2 receptor- $\alpha$-chain), CD45RO, cytotoxic T-lymphocyte associated antigen-4 (CTLA-4), and FoxP3 (the forkhead/winged helix transcription factor gene) $(18,19)$. Tregs suppress the activation and proliferation of both $\mathrm{CD}^{+}$and $\mathrm{CD}^{+} \mathrm{T}$ cells $(20,21)$. Tregs increase in patients with liver transplantation (22). Experimental liver transplantation models show that reinfusion of $\mathrm{CD} 4{ }^{+} \mathrm{CD} 25^{+}$Tregs can alter the immune response to graft both in vitro and in vivo. The present study was undertaken to explore methods for suppressing the immune rejection following liver transplantation. We report here that emodin has significant effects on suppressing the maturation of DCs and inducing Tregs, which is helpful for the alleviation of immune rejection after liver transplantation.

\section{Materials and methods}

Chemicals. Blood samples from healthy donors were obtained from the Wenzhou Red Cross Blood Center. Informed consent was obtained from all participants before blood donation following a study protocol approved by the Ethics Committee of the Second Affiliated Hospital of Wenzhou Medical College. The human leukocyte antigen (HLA-A2) phenotype was determined using monoclonal fluorescent antibody (BD Pharmingen) staining and flow cytometric analysis. A total of 
Table I. Comparison of surface phenotype of DCs with or without emodin treatment.

\begin{tabular}{lccccccr}
\hline Group & Case & HLA-DR $^{+}$ & CD80 & CD83 $^{+}$ & CD86 $^{+}$ & CD14 $^{+}$ & CD11c $^{+}$ \\
\hline Emodin + LPS & 8 & $83.6 \pm 6.9$ & $13.4 \pm 6.6^{\mathrm{a}}$ & $9.3 \pm 2.2^{\mathrm{a}}$ & $84.2 \pm 6.3$ & $8.4 \pm 2.8^{\mathrm{a}}$ & $95.5 \pm 3.1$ \\
LPS & 6 & $88.8 \pm 7.8$ & $39.3 \pm 8.6^{\mathrm{a}}$ & $30.7 \pm 5.6^{\mathrm{a}}$ & $95.4 \pm 3.2$ & $3.7 \pm 2.3^{\mathrm{a}}$ & $93.4 \pm 2.9$
\end{tabular}

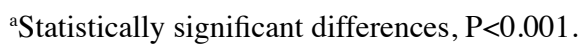

19 HLA-A2 ${ }^{+}$donors were enrolled in this study. Emodin (Sigma Aldrich, St. Louis, MO, USA) was dissolved in dimethylsulfoxide (DMSO, Sigma Chemicals, USA) and further diluted to a final concentration of $25,50,100,150$ and $200 \mu \mathrm{g} / \mathrm{ml}$.

DC culture. PBMCs were isolated from healthy donors by centrifugation on a Ficoll gradient. The cells $\left(2 \times 10^{7}\right.$ per well $)$ were allowed to adhere to plastic culture plates in RPMI-1640 medium supplemented with 10\% FBS (HyClone, USA) for $4 \mathrm{~h}$. Non-adherent cells were removed and frozen to be used as a source of T-lymphocytes in the subsequent stimulation experiments. Adherent monocytes were treated in AIM-V medium (Gibco, USA) with 1,000 units interleukin-4 (IL-4) (R\&D Systems, USA) and 1,000 U/ml of granulocyte-macrophage colony-stimulating factor (GM-CSF, R\&D Systems, Weisbaden, Germany), and cultured for 7 days at $37^{\circ} \mathrm{C}$ and $5 \% \mathrm{CO}_{2}$. LPS $(1 \mu \mathrm{g} / \mathrm{ml})$ was added on Day 7 to induce DCs maturation. On Day 7, different concentrations of emodin (25, $50,100,150$ or $200 \mu \mathrm{g} / \mathrm{ml}$ ) were added to the culture medium. DCs were then harvested at Day 10.

PBMCs and Tregs. PBMCs were cultured in RPMI-1640 with IL-2 (30 U/ml) for 7 days. Emodin was added on Day 2. PBMCs were re-fed with fresh RPMI-1640 plus IL-2 (30 U/ml) with or without emodin daily. On the Day 7, the PBMCs were collected and prepared to analysis of Tregs by fluorescence confocal microscopy (FCM).

Flow cytometric analysis. DCs were subjected to flow cytometric analysis. DCs were stained at $4^{\circ} \mathrm{C}$ in PBS with the following fluorescein isothiocyanate-labeled antibodies, anti-CD80, antiCD86, anti-CD83, anti-CD11c, anti-HLA-DR, anti-CD14 and anti-CD1- $\alpha$ (BD Pharmingen). After 30 min, cells were washed and the phenotype was analyzed. To determine the frequency and phenotype of Tregs in PBMCs, multicolor fluorescenceactivated cell sorting analysis was performed using the following antibodies, anti-CD4, anti-CD25, anti-CD62L, antiHLA-DR, anti-CD45RA, anti-CD45RO, anti-CD152, (BD Pharmingen), PE-conjugated anti-FoxP3 (Biolegend, USA) and anti-glucocorticoid induced tumor necrosis factor receptor (GITR) (R\&D Systems). Three-color or 4-color flow cytometry was conducted using a Becton-Dickinson FACSCalibur and the FlowJo7.0 software. Isotype-matched antibodies were used as controls for all the samples.

T-cell stimulatory capacity of $m D C s$. The T-cell stimulatory capacity of mDCs was determined in an allogeneic mixed lymphocyte reaction (MLR). Isolated mDCs were matured by LPS in the presence of emodin or the appropriate controls in culture medium. After $24 \mathrm{~h}$, the culture medium was removed and autologous $\mathrm{T}$ cells were added and co-cultured for 6 days. As a positive control, T cells were stimulated with phytohemagglutinin $(5 \mu \mathrm{g} / \mathrm{ml})$. During the last $16 \mathrm{~h}$ of the 6-day culture period, $0.5 \mu \mathrm{Ci}\left[{ }^{3} \mathrm{H}\right]$-thymidine (Amersham, Little Chalfont, UK) was added per well to determine $\mathrm{T}$ cell proliferation. All measurements were performed in triplicate, and $\left[{ }^{3} \mathrm{H}\right]$-thymidine incorporation was determined by liquid scintillation counting. The results are expressed as the mean of triplicate cultures. The SEM of the results never exceeded $15 \%$.

Cytokine measurements. Adherent PBMCs were cultured for 7 days with GM-CSF and IL-4. Cell-free culture supernatants were harvested after 96 h (Day 4), 120 h (Day 5), 144 h (Day 6), $168 \mathrm{~h}$ (Day 7) of further culture of the DCs at a concentration of $5 \times 10^{5} / \mathrm{ml}$ with or without emodin $(100 \mu \mathrm{g} / \mathrm{ml})$. IL-12p70 (Diaclone, Besancon, France), and IL-10 (Diaclone) release in the supernatants were measured by specific sandwich ELISA.

Statistical analysis. Continuous variables are expressed as the mean \pm SD. One-way analysis of variance and the Student's t-test were used to assess differences between the study groups. Significance was established at $\mathrm{P}<0.05$. The data were analyzed using the SPSS software version 11.0 (SPSS Inc., Chicago, IL).

\section{Results}

Characterization of DCs treated with emodin. To assess the effect of emodin in DCs maturation, DCs were cultured from adherent monocytes with GM-CSF and IL-4 for 7 days followed by treatment with emodin at a concentration of $100 \mu \mathrm{g} / \mathrm{ml}$ for 3 days. Photomicrographs were taken on Day 10 of culture with medium magnification (x40). LPS-treated DCs displayed typical dendritic morphology (Fig. 1A-D). However, emodin-treated DCs displayed immature dendritic morphology (Fig. 1E and F).

Emodin inhibits the up-regulation of co-stimulatory molecules on DCs. It is well known that CD86 and CD80 are co-stimulators of DCs and that CD83 is an important maturation marker for DCs. We assessed the maturation of DCs after emodin treatment using these markers. PBMCs were isolated from healthy donors and used for the generation of immature DCs (imDCs). We tested whether emodin can affect DC maturation. Surface expression of CD14, CD80, CD83, CD86, CD11c, CD1- $\alpha$ and HLA-DR on DCs with or without emodin treatment was measured before and after LPS stimulation. Treatment of imDCs for $72 \mathrm{~h}$ with LPS resulted in typical DC morphology and 


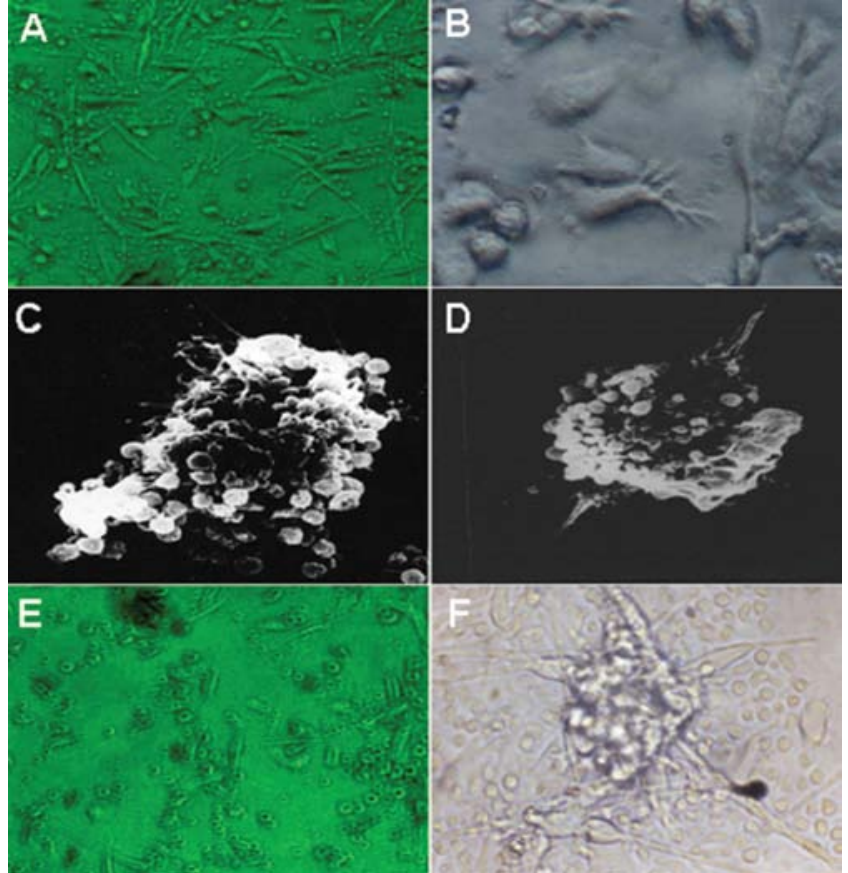

Figure 1. (A and B) Typical morphology of dendritic cells (DCs) as revealed by light and scanning electron microscopy. LPS-treated DCs display typical mature dendritic morphology under a light microscope (x40). (C and D) a scanning electron microscope (x15,000). (E and F) Emodin-treated DCs display immature dendritic morphology. induced significant maturation, as reflected by up-regulation of HLA-DR, CD86 and CD83 (Fig. 2 and Table I). However, the expression of the maturation marker CD83 and co-stimulator markers CD80/CD86 on DCs treated with emodin was lower than that on DCs without emodin treatment $(\mathrm{P}<0.05)$ (Fig. 2 and Table I).

Treatment of DCs with $100 \mu \mathrm{g} / \mathrm{ml}$ emodin for $72 \mathrm{~h}$ appeared to be optimal. Emodin concentrations $>150 \mu \mathrm{g} / \mathrm{ml}$ were toxic (induced DC apoptosis), whereas concentrations of emodin $<50 \mu \mathrm{g} / \mathrm{ml}$ did not induce any maturation (data not shown). Based on these results, we decided to only use the optimal concentration of $100 \mu \mathrm{g} / \mathrm{ml}$ for the treatment in DC cultures.

Emodin inhibits the production of IL-12 after in vitro stimulation. mDCs produce both IL-12 and IL-10 depending on the maturation stimulus. To further evaluate the effects of emodin on the maturation of DCs, we evaluated IL-12 or IL-10 production of DCs with emodin treatment. The results showed that emodin treatment resulted in a decrease of IL-12 production (Fig. 3). Indeed, only LPS-treated DCs produced a high level of IL-12p70 (Fig. 3). The capacity of DCs to produce IL-10 was not significantly suppressed by emodin treatment.

Emodin inhibits the T-cell stimulatory capacity of $m D C$. Since both the expression of costimulatory molecules and the

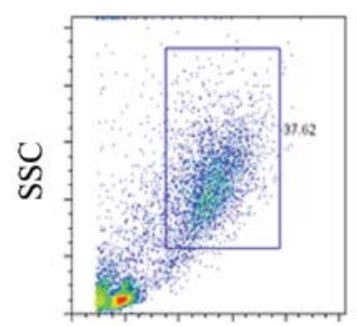

FSC

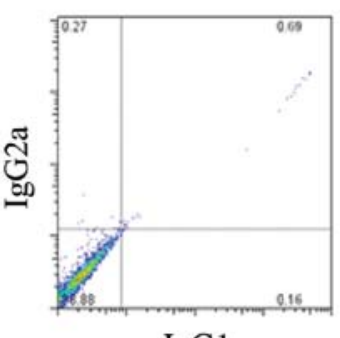

IgG1
$\operatorname{iDC}(5 d)$
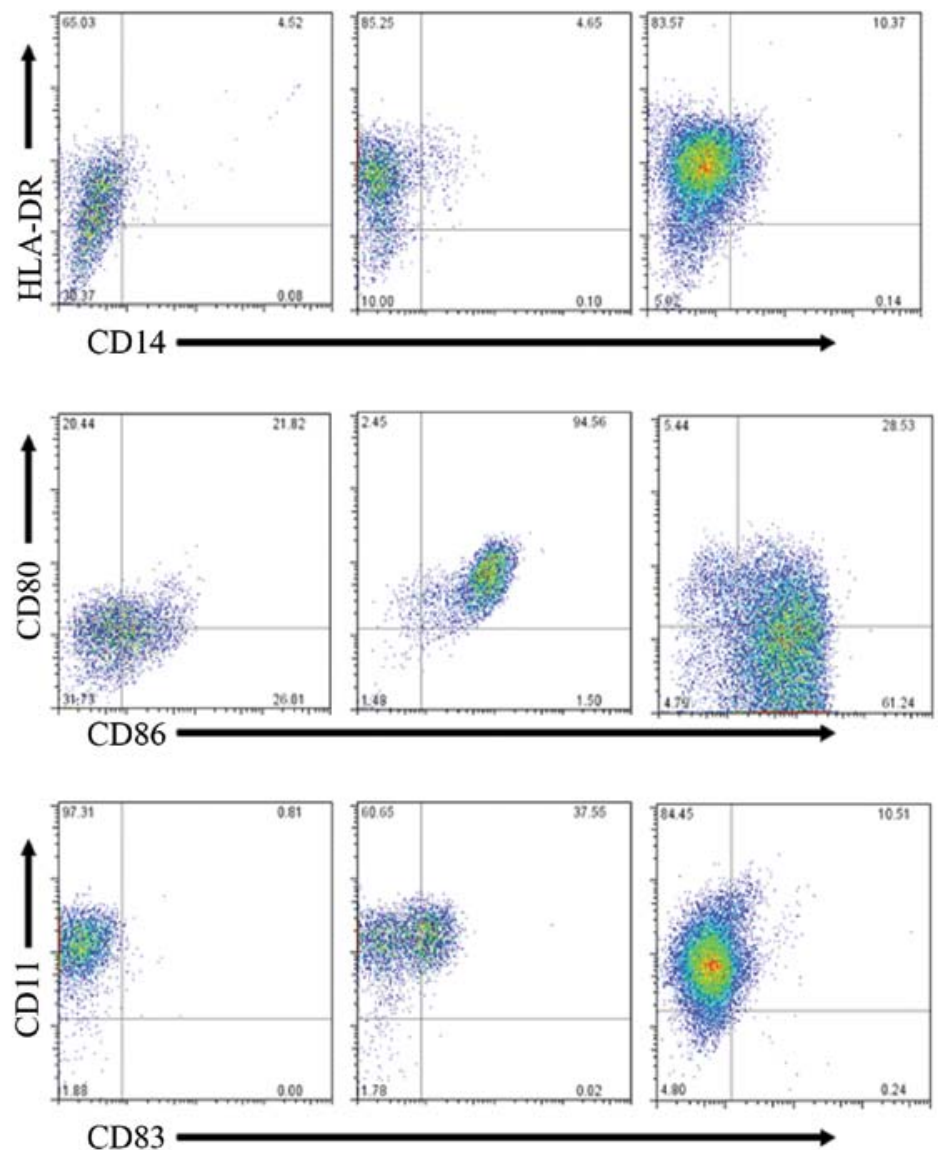

Figure 2. Emodin suppresses the expression of CD80, CD86 and CD83 on DCs LPS-pulsed DCs matured and showed an enhanced expression of CD80, CD86 and CD83. Treatment of immature DCs with LPS resulted in significant maturation, as reflected by the up-regulation of HLA-DR, CD86 and CD83. The expression of the maturation marker CD83 and co-stimulator markers CD80/CD86 on emodin-treated DCs was lower compared to untreated DCs $(\mathrm{P}<0.05)$. 


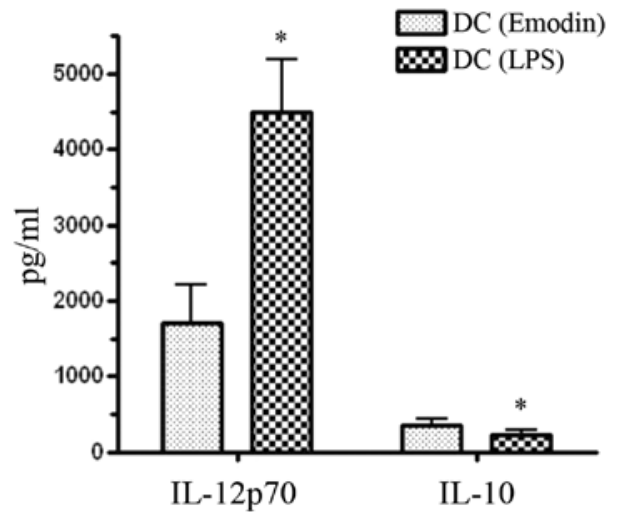

Figure 3. Emodin decreases IL-12p70 production of LPS-stimulated DCs. IL-12p70 production of LPS treated mDCs was significantly inhibited by emodin when compared with the non-emodin-treated group. ${ }^{*} \mathrm{P}<0.05$ compared with the emodin-treated DCs. The production of IL-10 was not significantly altered by emodin treatment. production of cytokines like IL-12 play a major role in T-cell activation by DCs, the effects of emodin on the T-cell stimulatory capacity of $\mathrm{mDCs}$ were determined in an allogeneic MLR. The T-cell stimulatory capacity of emodin-treated DCs is compared with those of immature DCs and LPS-treated DCs. Treatment of mature mDCs with LPS induced T-cell proliferation (Fig. 4), thus, mDCs treated with emodin showed an approximately 2 -fold reduction of T-cell proliferation. Likewise, T-cell proliferation was inhibited in the presence of emodin. This effect was dose-dependently regulated and observed with an emodin concentration as low as $25 \mu \mathrm{g} / \mathrm{ml}$.

Emodin treatment of DCs induces $C D 4^{+} C D 25^{+}$Tregs. One of the possible mechanisms by which emodin-treated DCs can reduce $\mathrm{T}$-cell proliferation is the induction of Tregs, which can actively suppress T-cell responses. The induction of this T-cell subset during MLRs was analyzed by the expression

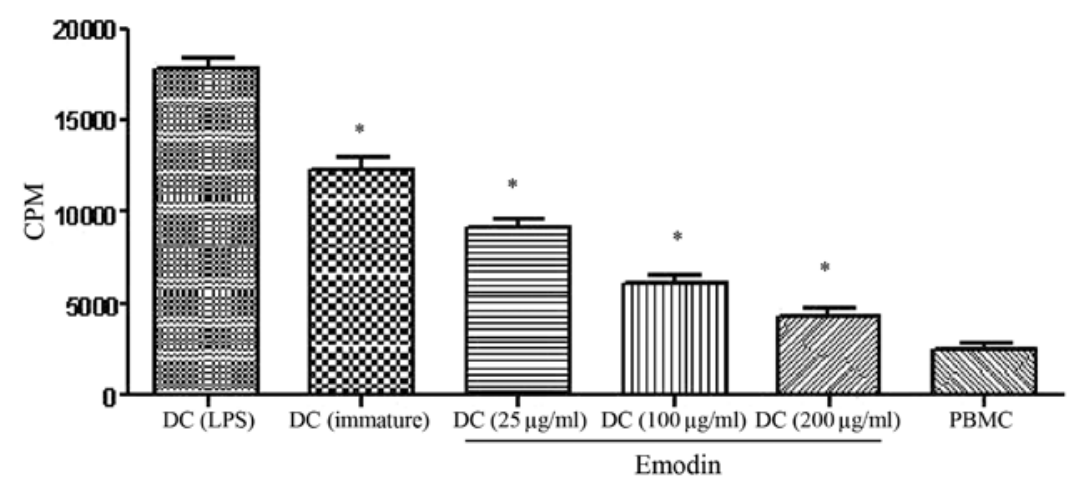

Figure 4. Emodin-treated DCs are inefficient in inducing T-lymphocyte proliferation. The T cell stimulatory capacity of emodin-treated DCs is compared with those of immature DCs and LPS-treated DCs. Treatment of mature mDCs with LPS induced T-cell proliferation. mDCs in the presence of emodin reduced the T-cell proliferation by approximately 2 -fold at all stimulator:responder ratios. " $\mathrm{P}<0.05$ compared with the emodin-treated DCs. This effect was dose-dependently regulated and observed with an emodin concentration as low as $25 \mu \mathrm{g} / \mathrm{ml}$.

A
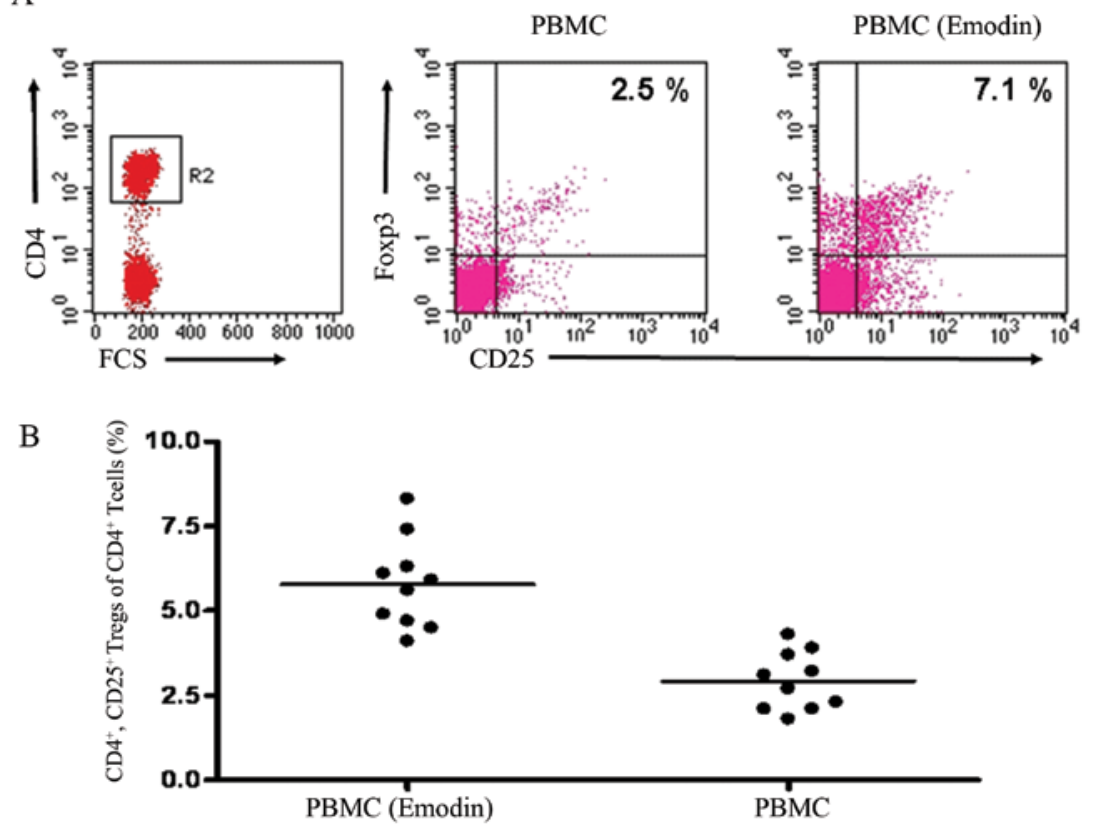

Figure 5. Emodin induces $\mathrm{CD} 4^{+} \mathrm{CD} 25^{+}$and $\mathrm{FoxP}^{+}$regulatory T cells (Tregs). The frequency of $\mathrm{CD}^{+}{ }^{+} \mathrm{CD} 25^{+}$Tregs is represented by the numbers of $\mathrm{CD} 4^{+} \mathrm{CD} 25^{+}$, FoxP $^{+}$Tregs. The frequency of circulating Tregs with emodin treatment was significantly higher than that in the group without emodin treatment $(6.23 \pm 1.03 \%$ and $3.67 \pm 0.73 \%, \mathrm{P}<0.01)$. 
of the regulatory T-cell specific transcription factor FoxP3. After 6 days of culture with non-treated mDCs, approximately $3.67 \pm 0.73 \%$ of $\mathrm{CD}^{+} \mathrm{T}$ cells could be defined as Tregs $\left(\mathrm{CD}^{+}{ }^{+} \mathrm{CD} 25^{+}\right.$and $\left.\mathrm{FoxP}^{+}\right)$(Fig. 5), while in emodin-treated $\mathrm{mDC}$, the percentage of $\mathrm{CD} 4{ }^{+} \mathrm{CD} 25^{+} \mathrm{FoxP}^{+}$Tregs reached $6.23 \pm 1.03 \%$. A significant difference in the number of Tregs was observed when $\mathrm{T}$ cells were stimulated with emodintreated mDCs.

\section{Discussion}

In the present study, we evaluated the effects of emodin on DCs and Tregs. Myeloid DCs were prepared from peripheral blood mononuclear cells of healthy human donors and treated with emodin at different concentrations. The phenotype and $\mathrm{T}$ cell stimulatory capacity of these DCs were analyzed. The results demonstrate that emodin inhibited maturation of DCs and IL-12p70 production, induced $\mathrm{CD} 4{ }^{+} \mathrm{CD} 25^{+}$Tregs and suppressed T-lymphocyte proliferation. There was a significant difference in CD80, CD86 and CD83 expressions between treated and untreated DCs.

Emodin is an active anthraquinone constituent of rhubarb extract and it possesses anti-atherosclerosis, anti-bacterial, anti-cancer, and vasorelaxant activities (1-6). Emodin has immunity modulation ability and could be useful in treating various inflammatory diseases (23-25). A previous study found that emodin inhibited the rejection of orthotopic liver transplantation in rats $(9,10)$, but the underlying mechanism is not clear. Yu et al (26) reported that emodin inhibited the proliferation of lymphocytes. In this study we analyzed the phenotype and function of monocyte-derived DCs in response to emodin treatment.

It is well known that CD86 and CD80 are co-stimulators of DCs and that CD83 is an important maturation molecule of DCs (27-29). The potency of DCs as APCs is correlated with their constitutive expression of high levels of cell-surface MHC class I and II antigens and co-stimulatory molecules CD80 and CD86 (28). These molecules serve to initiate and stabilize the interaction of DCs with $\mathrm{T}$ cells through the corresponding ligands in T cells. With LPS stimulation, CD83, CD86 and CD80 were up-regulated to approximately the same extent in DCs. Emodin has been demonstrated to inhibit the expression of maturation surface markers and the stimulatory ability of DCs. Our study further revealed the phenotype and maturation of DCs upon emodin treatment.

The low expression of CD83, CD86 and CD80 on emodintreated DCs suggests that emodin inhibits the maturation of DCs. Emodin reduced the levels of IL-12 in LPS-induced DCs. In addition, emodin-treated DCs are inefficient APCs in mixed lymphocyte reactions and the frequency of circulating Tregs in the emodin-treated group was significantly higher than in the non-treated group. It has been reported that Tregs, especially $\mathrm{CD} 4^{+} \mathrm{CD} 25^{+}$and FoxP $3^{+}$Tregs play a vital role in immunologic self-tolerance, anti-tumor immune responses, and transplantation (14-16). The increased number of $\mathrm{CD} 4^{+} \mathrm{CD} 25^{+}$Tregs in vivo may induce immune tolerance. Our results suggest that emodin increases the frequency of $\mathrm{CD}^{+} \mathrm{CD} 25^{+}$and Fox $3^{+}$ circulating Tregs, an effect which will be helpful in inducing immune tolerance in organ transplantation or autoimmune diseases.
The main findings of the present study are that emodin plays a key role in the inhibition of differentiation and maturation of DCs and enhancement of Tregs production, which may be helpful for the modulation of immune suppression and induction of immune tolerance.

\section{Acknowledgements}

We are grateful for funding support from the National Natural Science Foundation of China (Grant nos. 30572395 and 30973815).

\section{References}

1. Llovet JM, Burroughs A and Bruix J: Hepatocellular carcinoma. Lancet 362: 1907-1917, 2003.

2. Zhao XY, Qiao GF, Li BX, Chai LM, Li Z, Lu YJ and Yang BF: Hypoglycaemic and hypolipidaemic effects of emodin and its effect on L-type calcium channels in dyslipidaemic-diabetic rats. Clin Exp Pharmacol Physiol 36: 29-34, 2009.

3. Heo SK,Yun HJ, Park WH and Park SD: Emodin inhibits TNF-alpha-induced human aortic smooth-muscle cell proliferation via caspase- and mitochondrial-dependent apoptosis. J Cell Biochem 105: 70-80, 2008.

4. Chen H, Wei W, Guo Y, et al: Enhanced effect of gemcitabine by emodin against pancreatic cancer in vivo via cytochrome C-regulated apoptosis. Oncol Rep 25: 1253-1261, 2011.

5. Chen RF, Shen YC, Huang HS, et al: Evaluation of the anti-inflammatory and cytotoxic effects of anthraquinones and anthracenes derivatives in human leucocytes. J Pharm Pharmacol 56: 915-919, 2004.

6. Wei WT, Chen H, Ni ZL, et al: Antitumor and apoptosis-promoting properties of emodin, an anthraquinone derivative from Rheum officinale Baill, against pancreatic cancer in mice via inhibition of Akt activation. Int J Oncol 39: 1381-1390, 2011.

7. Park MY, Kwon HJ and Sung MK: Evaluation of aloin and aloeemodin as anti-inflammatory agents in aloe by using murine macrophages. Biosci Biotechnol Biochem 73: 828-832, 2009.

8. Du Y and Ko KM: Effects of emodin treatment on mitochondrial ATP generation capacity and antioxidant components as well as susceptibility to ischemia-reperfusion injury in rat hearts: single versus multiple doses and gender difference. Life Sci 77: 2770-2782, 2005.

9. Tong HF, Chen KJ, Chen H, et al: Emodin prolongs recipient survival time after orthotopic liver transplantation in rats by polarizing the Th1/Th2 paradigm to Th2. Anat Rec (Hoboken) 294: 445-452, 2011.

10. Lin SZ, Chen KJ, Tong HF, Jing H, Li H and Zheng SS: Emodin attenuates acute rejection of liver allografts by inhibiting hepatocellular apoptosis and modulating the Th1/Th2 balance in rats. Clin Exp Pharmacol Physiol 37: 790-794, 2010.

11. Sumpter TL, Abe M, Tokita D and Thomson AW: Dendritic cells, the liver, and transplantation. Hepatology 46: 2021-2031, 2007.

12. Bosma BM, Metselaar HJ, Tra WM, et al: Impairment of circulating myeloid dendritic cells in immunosuppressed liver transplant recipients. Clin Exp Immunol 149: 525-534, 2007.

13. Benseler V, McCaughan GW, Schlitt HJ, Bishop GA, Bowen DG and Bertolino P: The liver: a special case in transplantation tolerance. Semin Liver Dis 27: 194-213, 2007.

14. Sakaguchi S: Naturally arising $\mathrm{CD} 4^{+}$regulatory $\mathrm{T}$ cells for immunologic self-tolerance and negative control of immune responses. Annu Rev Immunol 22: 531-562, 2004.

15. Apostolou I, Verginis P, Kretschmer K, Polansky J, Hühn J and von Boehmer H: Peripherally induced Treg: mode, stability, and role in specific tolerance. J Clin Immunol 28: 619-624, 2008.

16. Waldmann H, Adams E, Fairchild P and Cobbold S: Regulation and privilege in transplantation tolerance. J Clin Immunol 28: 716-725, 2008.

17. Shevach EM, McHugh RS, Piccirillo CA and Thornton AM: Control of T-cell activation by $\mathrm{CD} 4{ }^{+} \mathrm{CD} 25^{+}$suppressor T cells. Immunol Rev 182: 58-67, 2001.

18. Fontenot JD, Gavin MA and Rudensky AY: FoxP3 programs the development and function of $\mathrm{CD} 4{ }^{+} \mathrm{CD} 25^{+}$regulatory T cells. Nat Immunol 4: 330-336, 2003. 
19. Fontenot JD, Rasmussen JP, Williams LM, Dooley JL, Farr AG and Rudensky AY: Regulatory T cell lineage specification by the forkhead transcription factor Foxp3. Immunity 22: 329-341, 2005.

20. Piccirillo CA and Shevach EM: Cutting edge: control of CD8 $\mathrm{T}$ cell activation by $\mathrm{CD} 4{ }^{+} \mathrm{CD} 25^{+}$immunoregulatory cells. $\mathrm{J}$ Immunol 167: 1137-1140, 2001.

21. Woo EY, Yeh H, Chu CS, et al: Cutting edge: regulatory T cells from lung cancer patients directly inhibit autologous $\mathrm{T}$ cell proliferation. J Immunol 168: 4272-4276, 2002.

22. Li W, Carper K, Zheng XX, et al: The role of FoxP3 ${ }^{+}$regulatory $\mathrm{T}$ cells in liver transplant tolerance. Transplant Proc 38: 3205-3206, 2006.

23. Lu HF, Lai KC, Hsu SC, et al: Involvement of matrix metalloproteinases on the inhibition of cells invasion and migration by emodin in human neuroblastoma SH-SY5Y cells. Neurochem Res 34: 1575-1583, 2009.

24. Ding Y, Zhao L, Mei H, et al: Exploration of emodin to treat alpha-naphthylisothiocyanate-induced cholestatic hepatitis via anti-inflammatory pathway. Eur J Pharmacol 590: 377-386, 2008.
25. Kitano A, Saika S, Yamanaka O, et al: Emodin suppression of ocular surface inflammatory reaction. Invest Ophthalmol Vis Sci 48: 5013-5022, 2007.

26. Yu CS, Yu FS, Chan JK, et al: Aloe-emodin affects the levels of cytokines and functions of leukocytes from Sprague-Dawley rats. In Vivo 20: 505-509, 2006.

27. Young JW, Koulova L, Soergel SA, Clark EA, Stein RM and Dupont B: The B7/BB1 antigen provides one of several costimulatory signals for the activation of $\mathrm{CD} 4^{+} \mathrm{T}-$ lymphocytes by human blood dendritic cells in vitro. J Clin Invest 90: 229-237, 1992.

28. Steinman RM: The dendritic cell system and its role in immunogenicity. Annu Rev Immunol 9: 271-296, 1991.

29. Martino A, Sacchi A, Volpe E, et al: Non-pathogenic mycobacterium smegmatis induces the differentiation of human monocytes directly into fully mature dendritic cells. J Clin Immunol 25: 365-375, 2005. 